\title{
Tips for computer vision syndrome relief and prevention
}

\author{
J. Tribley ${ }^{\mathrm{a}}$, S. McClain ${ }^{\mathrm{a}}$, A. Karbasi ${ }^{\mathrm{a}}$ and J. Kaldenberg ${ }^{\mathrm{a}, \mathrm{b}}$ \\ ${ }^{\mathrm{a}}$ New England College of Optometry, Boston, MA, USA \\ ${ }^{\mathrm{b}}$ New England Eye, Boston, MA, USA
}

\begin{abstract}
Keep an eye out for eye fatigue symptoms Computer-related vision symptoms such as eye fatigue have some com-
mon causes that should not be ignored. Visual display Terminals (VDTs)
cause symptoms such as eyestrain, visual discomfort, and visual fatigue
(Murata et al., 1996). Detecting the likely diagnosis and treating the
cause can result in improving performance of the user and lowering the
risk of ocular problems (Anshel, 2005). Children may also experience
the visual symptoms related to computer use. Many similar to those
experienced by adults such as eye discomfort, fatigue, blurred vision and headaches, dry eyes and other symptoms of eyestrain (Kozeis, 2009).
\end{abstract}

K. Murata, S. Araki, K. Yokoyama, K. Yamashita, T. Okumatsu and S. Sakou, Accumulation of VDT Work-Related Visual Fatigue Assessed by Visual Evoked Potential, Near Point Distance and Critical Flicker Fusion, Industrial Health 34(2) (1996), 61-69.

Symptoms can include headaches, eyestrain, blurry vision, dry eyes, irritated eyes, eye fatigue, light sensitivity, neck, back, and shoulder pain, and double vision

Limit the amount Limiting the amount of

of time you a dramatic impact on symptoms in front of the computer will have spend in front of the computer if puter user after working on a computer for 20 minutes, the user must a dramatic impact on symptoms associated with computer vision synpossible puter user after working on a computer for 20 minutes, the user must
look away at $20 \mathrm{ft}$ for at least 20 seconds. This can improve the work efficiency and prevent eye strain (Anshel, 2005; Misawa et al., 1984).

J. Anshel, ed., Visual Ergonomics Handbook. New York: Taylor and Francis, (2005).

It is also very important to limit computer use with children as they have N. Kozeis, Impact of computer use on children's vision, Hippokratia 13(4) (2009), 230-231.

J. Anshel, ed., Visual Ergonomics Handbook. New York: Taylor and Francis, (2005).

T. Misawa, K. Yoshino and S. Shigeta, An experimental study on the duration of a single spell of work on VDT (visual display terminal) performance. Sangyo Igaku 26(4) (1984), 296-302. a lower degree of self awareness and often do not notice discomfort or other symptoms associated with computer vision syndrome. gests that computer users have an eye exam before working on a computer and once a year thereafter. Individuals should be sure to tell their optometrist how often and where they use a computer as well as the distance they normally sit from their computer.

B.L. Cole, Do visual Display units cause visual problems? - a bedside story about the process of public health decision-making. Clinical and Experimental Optometry: Journal of the Australian Optometrical Association 86(4) (2003), 205-220.

Set up your com- Height and inclination of monitor has influence on the visual discomfort puter or laptop for both men and women. In a study by Rechichi, and Scullica (1990), properly to mini- it was shown that visual discomfort has a high correlation with height mize and relieve and inclination of computer monitor, therefore it is highly suggested symptoms the use of an ergonomic position of the computer monitor and chair. Izquierdo et al., 2007), found that smaller angle of gaze leads to more CVS symptoms than large angle (14 degrees or more).

In addition, improving the working environment such as screen reflections, glare from window or overhead lights, lighting quality, viewing angle of the computer screen, and screen design (contrast polarity, resolution and flicker) can improve the work environment for a computer user leading to decreased computer vision symptoms (Sheedy, 1996).

J.C. Izquierdo, M. García, C. Buxó and N.J. Izquierdo, Factors leading to the computer vision syndrome: an issue at the contemporary workplace, Bol Asoc Med 99(1) (2007), 21-28.

C. Rechichi and L. Scullica, Asthenopia and monitor characteristics, Istituto di Oftalmologia 13(89) (1990), 456-460.

J.E. Sheedy, The Bottom Line on Fixing Computer-Related Vision and Eye Problem, Journal of The American Optometric Association 67(9) (1996), 512-517.

Remember that a computer set up for an adult is not a proper set up for a child. Keep this in mind if you have children in your home so that you can adjust the computer to meet their needs as well as your own. 


\begin{tabular}{|c|c|}
\hline \multirow[t]{3}{*}{$\begin{array}{l}\text { Use Proper } \\
\text { Lighting and } \\
\text { Minimize Glare }\end{array}$} & $\begin{array}{l}\text { When using a computer the lighting should be half that of normal room } \\
\text { illumination. This can be done with dimmer switches, closing blinds } \\
\text { or shades, use of } 3 \text { way bulbs, or use of low intensity bulbs. Glare and } \\
\text { reflections on computer screens can also cause eye strain. Glare is an } \\
\text { issue with all monitors. CRT monitors cause more glare and potential } \\
\text { strain issues due to screen dynamics and the screen constantly being } \\
\text { "redrawn". }\end{array}$ \\
\hline & $\begin{array}{l}\text { The best way to minimize glare is to use an anti-glare cover over the } \\
\text { screen and use of flat screens when possible. }\end{array}$ \\
\hline & $\begin{array}{l}\text { Studies have found that proper lighting, using non reflective coatings } \\
\text { and elimination of glare are important factors for optimal visual display } \\
\text { design. Conditions of high illumination and sensitivity to glare due to } \\
\text { computer use was shown to increase reading time and decrease attention } \\
\text { to task (Grosso et al., 2007; Garcia and Wierwille, 1985; Maddocks and } \\
\text { Sharp, 1996). }\end{array}$ \\
\hline
\end{tabular}
Sharp, 1996).
Office Ergonomics Handbook. Fifth Editon. (2008). Ocupational Health Clinics For Ontario Workers.

T.W. Raasch, I.L. Bailey, P.A. Howarth, D.S. Greenhouse and S. Berman, Visual Performance at Video Display Terminals-Effects of Screen Color and Illuminant Type, Optometry And Vision Science 68(12) (1991), 924-929.

K.D. Garcia and W.W. Wierwille, Effect of Glare on Performance of a VDT ReadingComprehension Task, The Human Factors Society, 27(2) (1985), 16-173.

D. Grosso, A. Bellini, P. Zambelli, P. Troiano, M. Di Bisceglie, A. Bergamaschi and B. Piccoli, Work efficiency and lighting conditions: an experimental study, Geornale Italiano Medicina del Lavoro ed Ergonomia 29(3) (2007), 256-258.

J.D. Maddocks and K. Sharp, Effect of VDUs on the Eyes: Report of a 6-Year Epidemiological Study, Optometry and Vision Science, 73(8) (1996), 512-528.

Adjust and Clean Adjust the brightness so it is about the same as your surroundings and Your Computer adjust contrast as high as possible to eliminate discomfort

Screen

Dust may also impair one's vision when viewing a computer screen by affecting the glare, so be sure all monitors or screens are clean and free of dust.

Office Ergonomics Handbook. Fifth Editon. (2008). Ocupational Health Clinics for Ontario Workers.

B.L. Cole, J.D. Maddocks and K. Sharpe, Effect of VDUs on the Eyes: Report of 6-Year Epidemiological Study, Optometry and Vision Science 73(8) (1996), 512-528.

Make Sure You The environment, including poor lighting, focusing on the VDT, and Are Blinking blinking helps to fend of dryness and irritation in your eyes and studies show that people blink less frequently when using computers (Computer Eye Strain 2008). If you experience dry eye symptoms ask your doctor about artificial tears for use when using a computer

Poor light environment and viewing conditions lead to eye squint. This is the natural reaction of eye muscles under the poor condition in order to cut down on the brightness of the source and put the image into focus to see well. Studies have shown that eye squint reduces the blink rate, an important factor causing dry eye. Dry eye is another cause of eye strain and its associated symptoms (Sheedy, 2007).

Focusing too much while looking at the computer screen causes less blinking, this can cause uneven distribution of tear film over eye causing dry eye. Although screen glare and character size don't affect blink rate, studies have shown that a visual demanding computer work can decrease the blink rate from 24 to 5 blinks per minute (Helland et al., 2007).

Another research was done on the analyses of the eyeblink rate of volunteers before and during video display terminal use. It showed that at $22.5^{\circ} \mathrm{C}$ and 40 percent humidity, the mean $( \pm \mathrm{SD})$ rate of blinking was $22 \pm 9$ per minute under relaxed conditions and $7 \pm 7$ per minute while the subjects were viewing text on a video display terminal. Looking down while reading a book negates the reduced blinking rate but that is not the case while using the computer since the eyes must be wide open during the computer use. This can also cause the tear film to evaporate more (Tsubota, Nakamori, 1993).
K. Tsubota and K. Nakamori, Dry eyes and video display terminals, The New England Journal of Medicine 328(8) (1993), 584.

J.E. Sheedy, The physiology of eyestrain, Journal of Modern Optics 54(9) (2007), 1333-1341.

Magne Helland, Gunnar Horgen, Tor Martin Kvikstad, and Arne Aarås. (2007). Do Background Luminance Levels or Character Size Effect the Eye Blink Rate During Visual Display Unit (VDU) Work. American Academy of Optometry, 4566, 65-74. 

back, and shoulder pain, take frequent breaks. Make sure to stand up New York: Taylor and Francis, (2005). and move as well as look away from the computer.

Take frequent work break (at least once per hour) in order to prevent the eye strain associated by prolong eye work (e.g. Levy et al., 2005). It also helps the muscles of the eye to relax, decreasing the eye fatigue and headache. Maintaining a certain posture for long period of time can cause muscular and ocular problems. Variation in posture while sitting behind the computers can improve the symptoms associated with Computer Vision Syndrome.

Research has shown that taking frequent breaks while using the computer increases the efficiency and relaxes the accommodative system (Fenety and Walker, 2002; McLean et al., 2001). In general, taking a break for $5-10 \mathrm{~min}$ is better than taking a longer break every 2 or 3 hours (Thomson, 1998). For every continuous 1-2 hour of computer use 1015 minutes of break away from the computer terminal is recommended in some literatures (Koh et al.,1994).

Consider Com- To maximize comfort when at your computer talk to your optometrist puter Eyewear about a customized prescription made especially for computer working distance. This is especially important if you wear contacts, which can become dry and uncomfortable during computer work, or when using bifocals or progressives, which may not be optimal for computer distances.

A study of the computer vision syndrome of 79 VDT users (Visual Display Terminal) showed that computer glasses reduced the symptoms in these users over the 15 week period (Wallin et al., 1994).
B. Levy, G. Wagner, K. Rest and J. Weeks, Preventing Occupational Disease and Injury. American Health Association, 200. (2005)

A. Fenety and J.M. Walker, Short-term effects of workstation exercise on musculoskeletal discomfort and postural changes in seated video display unit workers, Physical Therapy 82(6) (2002), 578-589.

W.D. Thomson, Eye problems and visual display terminals-the facts and the fallacies, Ophthal Physiol Opt 18(2) (1998), 111-119.

J.D. Maddocks and K. Sharp, Effect of VDUs on the Eyes: Report of a 6-Year Epidemiological Study, Optometry and Vision Science 73(8) (1996), 512-528.

L. Wan, Task-specific computer glasses: understanding needs, reaping benefits, Occupational Health and Safety 61(3) (1992), 50-52.

J.A. Wallin, Z. Zhu, J.L. Jacobsen and S.D. Jacobsen, A preliminary study of the effects of computer glasses on reported VDT user symptoms: a field study, Journal of Safety Research 25(2) (1994), 67-76.

Guidelines for work with VDUs. (1991). Ministry of Labour, Singapore.

You or You Child is Sitting

From the Computer Screen
It is important for parents and teachers to monitor how far the children sits from the computer screen. There is a difference between retinal images when eyes are shifted from distance to near. In order to adapt to this change, eyes accommodate which means they change the thickness of the lens (Mon-Williams et al., 1999). Sitting close to the computer may cause excess accommodation. This may lead to over working the ciliary muscles of the eye therefore inducing some symptoms of CVS such as eye fatigue and headache. Although viewing the computer screen from a distance $(48.42$ and $65.33 \mathrm{~cm}$ ) causes more accommodation and convergence among people working with computer than those who do not work behind computer screen (Piccoli et al., 1996), according to Guidelines for work with VDUs the safe distance from the computer screen is between $45 \mathrm{~cm}$ and $70 \mathrm{~cm}$ (Guidelines for work with VDUs, 1991). In another study it was shown that visual strain on computer users is more at $50 \mathrm{~cm}$ than $100 \mathrm{~cm}$ with characters twice as large.
W. Jaschinski, Eyestrain in VDU users: Viewing distance and the resting position of ocular muscles, Human Factors 33(1) (1991), 69-83.

M. Mon-Williams, R. Burgess-Limerick, A. Burgess-Limerick and J. Wann, Vertical gaze direction and postural adjustment: An extension of the Heuer model, Journal of Experimental Psychology: Applied 5(1) (1999), 35-53.

B. Piccoli, M. Braga, P.L. Zambelli and A. Bergamaschi, Viewing distance variation and related ophthalmological changes in office activities with and without VDUs, Institute of Occupation Health 39(5) (1996), 719-728. 